\title{
Contribuições do Estágio de Docência em uma turma da UFRR, na Disciplina de Didática da Matemática, Fundamentada na Teoria Histórico-Cultural
}

\author{
Contributions of the Teaching training in a class at UFRR, in the \\ Mathematics Didactics Discipline, Based on Historical-Cultural Theory.
}

Contribuciones de la Pasantía Docente en clases de la UFRR, en la asignatura de Didáctica de la Matemática, fundamentada en la Teoría Histórico-Cultural

\author{
Gilmara Batista Souza (gilgbsouza@gmail.com) \\ Universidade Estadual de Roraima.
}

Cleuma Ferreira Artimandes Morais (cleuma.artimandes.morais@ gmail.com) Universidade Estadual de Roraima.

Neide Aparecida Costa Tolentino Tiburtino (neide981115717@ gmail.com) Universidade Estadual de Roraima.

Héctor José García Mendoza (hector.mendoza@live.com)

Universidade Estadual de Roraima.

Edileusa do Socorro Valente Belo (edileusabelo20@gmail.com)

Universidade Estadual de Roraima.

Resumo: A pesquisa surgiu durante a experiência de um estágio de docência no ensino superior, componente curricular obrigatório do Programa de Pós-graduação em Ensino de Ciências, da Universidade Estadual de Roraima. O objetivo foi verificar as contribuições da Atividade de Situações Problema Docente, fundamentada na teoria Histórico-Cultural, para licenciandos em Matemática, no âmbito da disciplina Didática da Matemática, ofertada pela Universidade Federal de Roraima. A zona de desenvolvimento proximal, um dos principais elementos presentes na Histórico-Cultural de Vygotsky, assim como as teorias da Atividade de Leóntiev, da Formação por Etapas das Ações Mentais de Galperin e o ensino problematizador de Majmutov, nortearam as atividades dessa pesquisa. Quanto aos procedimentos metodológicos, seguindo uma abordagem qualitativa, a pesquisa foi desenvolvida a partir de quatro momentos: diagnóstico; planejamento; execução do planejamento; retroalimentação e correção. Como resultados, constatou-se que os estudantes conseguiram realizar a sequência didática, simulando aulas contemplando um objeto de conhecimento matemático, do Ensino Fundamental Anos Finais e Ensino Médio. Como instrumento avaliativo final, os alunos apresentaram um relatório, contextualizando e descrevendo os trabalhos realizados, relacionando-os com as teorias estudadas.

Recebido em: 10/02/2021

Aceite em: 09/08/2021 
Palavras-chave: Didática da Matemática; Atividade de Situações Problema Docente; Estágio de Docência; Teoria Histórico-Cultural.

Abstract: The research emerged during the experience of a teaching internship in higher education, a mandatory curricular component of the Graduate Program in Science Teaching, at the State University of Roraima. The objective was to verify the contributions of the Teaching Problem Situations Activity, based on Historical-Cultural theory, for graduates in Mathematics, within the scope of Didactics of Mathematics, offered by the Federal University of Roraima. The zone of proximal development, one of the main elements present in Vygotsky's Historical-Cultural, as well as the theories of Leóntiev's Activity, of Galperin's Stage Formation of Mental Actions and Majmutov's problematizing teaching, guided the activities of this research. As for the methodological procedures, following a qualitative approach, the research was developed from four moments: diagnosis; planning; planning execution; feedback and correction. As a final assessment tool, students presented a report, contextualizing and describing the work carried out, relating them to the theories studied.

Keywords: Didactics of Mathematics; Teaching Problem Situations Activity; Teaching Internship. Historical-Cultural Theory.

Resumen: La investigación surgió durante la experiencia de una pasantía docente en la educación superior, componente curricular obligatorio del Programa de Posgrado en Enseñanza de las Ciencias, en la Universidad Estatal de Roraima. El objetivo es verificar las contribuciones de la Actividad de Situaciones Problema Docente, con base en la teoría Histórico-Cultural, para Licenciados en Educación con especialidad en Matemáticas, dentro del ámbito de Didáctica de las Matemáticas, que ofrece la Universidad Federal de Roraima. La zona de desarrollo próximo, uno de los principales elementos presentes en el histórico-cultural de Vygotsky, así como en las teorías de la actividad de Leóntiev, de la formación por etapas de las acciones mentales de Galperin y de la enseñanza problematizadora de Majmutov, guiaron las acciones de esta investigación. En cuanto a los procedimientos metodológicos, tiene un enfoque cualitativo, la investigación se desarrolló a partir de cuatro momentos: diagnóstico; planificación ejecución de la planificación; retroalimentación y corrección. Como resultado, se encontró que los estudiantes lograron llevar a cabo la secuencia didáctica, simulando clases contemplando un objeto de conocimiento matemático, de la Educación Secundaria y Preuniversitaria. Como herramienta de evaluación final, los estudiantes presentaron un informe, contextualizando y describiendo el trabajo realizado, relacionándolos con las teorías estudiadas

Palabras-clave: Didáctica de la Matemática; Actividad de Situación Problema Docente; Pasantía Docente; Teoría histórico-cultural.

\section{INTRODUÇÃO}

Esta pesquisa é resultado da experiência de um estágio de docência no ensino superior, componente curricular obrigatório do Programa de Pós-graduação em Ensino

Recebido em: 10/02/2021

Aceite em: 09/08/2021 
de Ciências, da Universidade Estadual de Roraima ${ }^{1}$, que busca oportunizar ao mestrando uma relação entre teoria e prática da docência no ensino superior, com o objetivo de desenvolver no profissional habilidades necessárias para sua prática, sob o olhar dos professores orientadores.

A formação de professores tem sido discutida por diversos teóricos, como por exemplo, Pimenta e Anastasiou (2010), Morosini (2001), Gonçalves (2006), Belo (2012; 2018), Alves e Heckler (2018) e Barcelos et al. (2020). Os autores apontam que tem sido dada prioridade à formação científica em detrimento a pedagógica, sob a alegação de que dominar o objeto de conhecimento é essencial para ser um bom professor, desconsiderando a importância do ato de planejar.

No decorrer da formação de professores de Matemática e áreas afins, ainda é perceptível que a disciplina Didática vem sendo ministrada por docentes, sem formação nessas áreas, ocasionando déficits na transposição de objetos de conhecimento. Com frequência, a disciplina em discussão tem sido ministrada por pedagogos, com formação mais geral, sem habilidades específicas relacionadas aos conteúdos matemáticos. Outro aspecto a ser analisado nos cursos de Licenciatura em Matemática é que o corpo docente precisa assumir o papel de agente formador com uma visão didática, possibilitando ao acadêmico realizar transposição de conteúdos, quando estiver atuando em sala de aula.

A Didática da Matemática é de suma importância, por ser base fundamental na formação de futuros docentes de Matemática, oportunizando assim o conhecimento e a vivência do ambiente escolar, como um espaço que aperfeiçoa o processo de ensino e aprendizado dessa área de ensino, com interação entre teoria e prática, refletindo sobre as tarefas realizadas no decorrer dessa disciplina. Dessa forma, as teorias poderão nortear para além das práticas pedagógicas, com reflexões a partir das mesmas, conforme esclarece Pimenta e Lima (2012, p. 43):

O papel das teorias é iluminar e oferecer instrumentos e esquemas para análise e investigação que permitam questionar as práticas institucionalizadas e as ações dos sujeitos e, ao mesmo tempo, colocar elas próprias em

\footnotetext{
${ }^{1}$ Parte deste artigo foi apresentado e publicado nos Anais. XIII Encontro Nacional de Educação Matemática (ENEM), Cuiabá/MT. 2019. SOUZA, G. B.; MENDOZA, H. J. G.; BELO, E. S. V.; DELGADO, O. T. Estágio de Docência no Ensino Superior na disciplina de Didática da Matemática fundamentada na Teoria histórico-Cultural.
}

Recebido em: 10/02/2021

Aceite em: 09/08/2021 
questionamento, uma vez que as teorias são explicações sempre provisórias da realidade.

As tarefas de estágio, foram organizadas a partir de um planejamento, orientado pela ementa da disciplina Didática da Matemática, considerando os seguintes aspectos: a) fundamento teórico sobre a didática como atividade pedagógica, componentes do processo didático e elementos da didática; b) didática no ensino da matemática a partir de uma teoria de aprendizagem; c) avaliação e planejamento do processo de ensino e aprendizagem da matemática; d) recursos didáticos no ensino da matemática. O plano de ensino da disciplina foi elaborado em conjunto com o orientador do estágio e professora responsável pela disciplina da UFRR.

Considerando as teorias da aprendizagem, optou-se por aplicar a Teoria HistóricoCultural de Vygotsky, juntamente com a Atividade de Leóntiev, Teoria de Formação por Etapas das Ações Mentais de Galperin, Ensino Problematizador de Majmutov e Atividade de Situações Problema Docente, de Mendoza e Tintorer (2018a, 2018b).

Neste contexto, esta pesquisa buscou verificar as contribuições da Atividade de Situações Problema Docente, com fundamentos na teoria Histórico-Cultural, para licenciandos em Matemática, no âmbito da disciplina Didática da Matemática, ofertada pela Universidade Federal de Roraima.

O estudo foi realizado no período de 7 de janeiro a 15 de fevereiro de 2019 , totalizando sessenta horas. Participaram dessa pesquisa três licenciandos em Matemática, que se encontravam cursando o quarto semestre, devidamente matriculados, na Disciplina de Didática da Matemática, ofertada no período de férias. Os alunos foram identificados como A1, A2 e A3, visando análise posterior dos dados.

\section{TEORIA HISTÓRICO CULTURAL DE LEV VYGOTSKY}

A Teoria Histórico Cultural - THC foi elaborada na antiga União Soviética, entre as décadas de 1920 e 1930, a partir dos estudos de Vygotsky, sendo a partir de então inserida nos meios educacionais de diversos países, incluindo o Brasil. Sua teoria tem como princípio fundamental o sujeito que está inserido em um contexto, que traz consigo conceitos pré-estabelecidos, sendo a partir da interação com o meio que esse sujeito vai se apropriar de novas culturas, signos e práticas sociais. Nesses espaços ocorrem

Recebido em: 10/02/2021

Aceite em: 09/08/2021 
processos interpsíquicos, nos quais as relações com o outro promovem mudanças expressivas na conduta do indivíduo, fazendo com que ele se aproprie de elementos externos, com transformações dos seus processos mentais e da sua maneira de se relacionar com o mundo.

Partindo da mediação, caracterizada pela relação do homem com o mundo e os outros homens, é que as funções psicológicas superiores, especificamente humanas, se desenvolvem. Para Vygotsky (2005), o instrumento e o signo são elementos básicos responsáveis pela mediação. Essa visão traz consigo ideias inspiradas na teoria marxista, segundo a qual o homem " [...] por meio do uso de instrumentos, modifica a natureza, e ao fazê-lo, acaba por modificar a si mesmo [...]” (MOYSÉS, 1997, p. 23).

Segundo Vygotsky, o conceito de zona de desenvolvimento proximal é a distância entre o nível de desenvolvimento real, que corresponde à solução independente do problema, e o nível de desenvolvimento potencial, que requer a orientação de outra pessoa, como professores ou amigos que se mostram mais capazes.

Fica evidenciado que a etapa zero do processo de ensino e aprendizagem é representada pelo disparador, objeto de interesse do professor, para motivar os alunos. $\mathrm{Na}$ primeira etapa, cabe ao professor planejar e orientar as ações da atividade, considerando a zona de desenvolvimento real, na expectativa de que os estudantes compreendam os objetos de conhecimento estudados, alcançando a zona de desenvolvimento potencial. Espera-se que na segunda etapa os estudantes realizem as ações propostas. Na terceira etapa, cabe ao professor explicar as ações (formação de conceitos e pensamento teórico), de modo que na quarta etapa o aluno possa transferir as ações para novos contextos e, por último, proceder com a internalização das ações.

\section{ATIVIDADE DE SITUAÇÕES PROBLEMA DOCENTE NO ENSINO E} APRENDIZAGEM MATEMÁTICA

Conforme afirma Núñez (2018, p. 162) para acontecer a aprendizagem, o professor organiza e planeja, uma vez que "o produto da aprendizagem é a orientação no plano mental, que potencializa o desenvolvimento integral de quem aprende, nesse caso, os futuros professores, e seu desenvolvimento profissional". Diante do exposto, a Base Orientadora da Ação (BOA) deverá ser estabelecida pelos alunos com a orientação da

Recebido em: 10/02/2021

Aceite em: 09/08/2021 
professora. Nessa etapa, os objetivos da atividade serão apresentados e os alunos serão direcionados sobre a tarefa que realizarão, discutindo as formas em que a mesma será executada.

Núñez (2018), seguindo as ideias de Galperin, apresenta o conceito do Esquema da Base Orientadora Completa da Ação (EBOCA) como uma ferramenta didática a ser planejada e elaborada pelo professor. Deve contemplar as ações de execução e controle presentes no processo de ensino e aprendizagem. Núñez e Ramalho $(2017$, p. 6) dizem que, por meio do Invariante Operacional (IO), se contemplam os dois modelos de EBOCA: o objetivo (que é classificatório) e o da ação por meio de um "sistema de operações da ação, o que chamamos invariante operacional”. Desta maneira, se destaca a necessidade de um esquema minucioso com as operações presentes nas ações do professor e do aluno.

Neste contexto, os atores envolvidos no processo de ensinagem precisam ampararse de um norteamento metodológico, cabendo ao aluno guiar-se pela BOA com um acompanhamento docente nos processos de orientação, execução e controle. Serão direcionados e diagnosticados pelas características das ações primárias e secundárias, enquanto o professor precisa elaborar o EBOCA, o qual reunirá todas as ações e operações necessárias em prol do objetivo desejado, a aprendizagem.

Para isso, foi utilizada a estratégia de resolução de problemas, conhecida como Atividade de Situações Problema Docente, desenvolvida por Mendoza e Tintorer (2017, 2018b) a partir de Majmutov, definida como uma atividade de estudo que está orientada pelo objetivo de resolver problemas docentes, na zona de desenvolvimento proximal, em um contexto de ensino e aprendizagem, no qual exista uma interação entre o professor, o estudante e a tarefa com caráter problematizador, fazendo uso das tecnologias digitais e outros recursos didáticos. A Atividade de Situações Problema Docente compreende as seguintes ações e operações:

Formular o problema docente $\left(1^{a}\right.$ ação): analisar a situação problema para determinar os elementos conhecidos e desconhecidos; estudar os dados e as condições da situação problema; determinar o buscado a partir de problema fechado (objetivo definido) ou aberto (objetivo não preciso).

Recebido em: 10/02/2021

Aceite em: 09/08/2021 
Construir o núcleo conceitual ( $2^{a}$ ação): determinar o nível de partida dos estudantes relacionado com os conhecimentos sobre o elemento conhecido e sua atualização se for necessário; estabelecer relações entre os conhecidos e desconhecidos, desde os pontos de vista conceitual e procedimental por meio de novas tarefas mais simples como realização de experimentos, analogia, intuição e suposição de hipóteses.

Solucionar o problema docente ( $3^{a}$ ação): aplicar o método lógico-analítico ou heurístico ou combinação de ambos para determinar os nexos entre o conhecido e desconhecido; determinar o buscado.

Interpretar a solução ( $4^{a}$ ação): verificar se a solução corresponde com o buscado e as condições do problema; analisar os resultados obtidos para encontrar possíveis novas relações conceitual e/ou procedimental com elementos anteriormente conhecidos. Momento importante para consolidar a aprendizagem consciente, além de permitir a exploração de novos problemas de forma mais eficaz.

De acordo com Majmutov (1983), o Problema Docente está relacionado à atividade de estudo do aluno. A contradição objetiva da tarefa entre os dados e as condições, pode converter-se na força motriz do pensamento, somente no caso em que se transforme na consciência do estudante, na contradição entre o conhecido e desconhecido.

Recomenda-se utilizar a Atividade de Situações Problema Docente - ASPD para aproximar o objeto de estudo ao aluno. Por sua vez, a teoria de Galperin pode contribuir com a organização do processo de aprendizagem, considerando a zona de desenvolvimento proximal, mediada por ações de problematização na perspectiva de Majmutov.

\section{ORGANIZAÇÃO E MÉTODOS DA PRÁTICA PEDAGÓGICA}

A pesquisa de cunho qualitativo foi realizada no período de 07 de janeiro a 15 de fevereiro de 2019, totalizando sessenta horas de estágio, na disciplina Didática de Matemática, do curso de Licenciatura em Matemática, da Universidade Federal de Roraima. Os participantes desta pesquisa foram três licenciandos, devidamente matriculados na disciplina, concentrada nas férias.

Visando a coleta e análise qualitativa dos dados, os acadêmicos foram identificados pelos códigos: A 1, A 2 e A 3. Pensando na aprendizagem com objetivo educativo e

Recebido em: 10/02/2021

Aceite em: 09/08/2021 
fomentador do desenvolvimento, Vygotsky (1988), por meio dos conceitos de Zona de Desenvolvimento Proximal (ZDP), Interação Social e Mediação, mostra que devemos valorizar as habilidades do aluno, buscando novas formas e instrumentos avaliativos, substituindo a interpretação de natureza excludente, propondo uma avaliação como processo que pressupõe inclusão e multiplicidade dos futuros professores de matemática.

A pesquisa configurou-se como um estudo de caso, uma vez que nos interessou estudar algo singular, na busca por retratar a realidade, com interpretação e análise do objeto, no contexto em que ele se encontra (FIORENTINI e LORENZATO, 2010).

Destaca-se que a ementa da referida disciplina, foi utilizada como norteadora das ações em sala de aula, a qual objetivou aplicar a didática no processo de ensino e aprendizagem Matemática a partir de uma teoria de aprendizagem. No Quadro 1, é possível observar a organização da Atividade de Situações Problema Docente.

Quadro 1- Atividade Situações Problema Docente desenvolvida na ensinagem.

\begin{tabular}{|c|c|}
\hline \multicolumn{2}{|c|}{ ETAPAS DA SEQUÊNCIA DIDÁTICA } \\
\hline \multicolumn{2}{|c|}{ PRIMEIRO MOMENTO: Formular o Problema (Diagnóstico). } \\
\hline $\begin{array}{l}\text { ATIVIDADE SITUAÇÕES } \\
\text { PROBLEMA DOCENTE }\end{array}$ & HABILIDADE \\
\hline Avaliação diagnóstica $\operatorname{lar} \Theta S \mathrm{C}$ & $\begin{array}{l}\text { Identificar a situação problema que os licenciandos poderiam } \\
\text { enfrentar para construção do problema docente. }\end{array}$ \\
\hline \multicolumn{2}{|c|}{ SEGUNDO MOMENTO: Construir o Núcleo Conceitual (planejamento). } \\
\hline $\begin{array}{l}\text { Elaboração e planejamento do processo } \\
\text { de ensino aprendizagem. }\end{array}$ & $\begin{array}{l}\text { Planejar o processo de ensino aprendizagem. Conduzir os } \\
\text { alunos a avançar da zona de desenvolvimento real à potencial. }\end{array}$ \\
\hline \multicolumn{2}{|c|}{ TERCEIRO MOMENTO: Solução do Problema Docente (execução). } \\
\hline $\begin{array}{l}\text { A execução do planejamento no processo } \\
\text { de ensino e Aprendizagem. }\end{array}$ & $\begin{array}{l}\text { Desenvolver habilidades com atividades de situações problema } \\
\text { Docentes. Sequência didática e elaboração de planos de aula. }\end{array}$ \\
\hline \multicolumn{2}{|c|}{ QUARTO MOMENTO: Interpretação da Solução (retroalimentação e correção). } \\
\hline $\begin{array}{l}\text { Avaliação e retroalimentação do processo } \\
\text { de ensino e aprendizagem na resolução de } \\
\text { problemas como metodologia de ensino. }\end{array}$ & $\begin{array}{l}\text { Verificar a aprendizagem dos acadêmicos. Entrega do relatório } \\
\text { além de apresentar uma aula para seus colegas, mestranda } \\
\text { estagiária e professor responsável pela disciplina e supervisor } \\
\text { da disciplina. }\end{array}$ \\
\hline
\end{tabular}

FONTE: Autores, 2019.

Recebido em: 10/02/2021

Aceite em: 09/08/2021 
O primeiro momento - realizado pela mestranda estagiária, orientador e professora responsável pela disciplina - consistiu na identificação da situação problema que os licenciandos poderiam enfrentar, por meio de instrumento diagnóstico, buscando a construção do problema docente. Este momento teve como objetivo verificar o conhecimento prévio (conhecido) e as habilidades dos licenciandos relacionadas ao desconhecido. Observou-se também o domínio ou não dos licenciandos frente aos prérequisitos para cursar a disciplina Didática Geral e Psicologia na Educação, visando a aprendizagem de novos objetos de conhecimento.

No segundo momento, posterior a formulação do problema docente, foi planejado o processo de ensinagem frente às metodologias de ensino, com coleta de dados adicionais. Também ocorreu a formulação da BOA, estabelecida e executada pelos alunos com a orientação da professora, além de uma apresentação do conceito da EBOCA: Esquema da Base Orientadora Completa da Ação, como uma ferramenta didática a ser planejada e elaborada pelo professor, a qual deve contemplar as ações de execução e controle, presentes no processo de ensino e aprendizagem. Desta maneira, se destacou a necessidade de um esquema minucioso com as operações presentes nas ações do professor e do aluno.

No terceiro momento, que corresponde à solução do problema docente, ocorreu a execução do planejamento do processo de ensino e aprendizagem e avaliação da resolução de problemas, como metodologia de ensino, fundamentados nas ações da Atividade de Situações Problema Docente e nas etapas mentais. Os objetos de conhecimento foram organizados previamente com os professores titulares da disciplina, conforme ementa do curso, sugerindo a divisão das tarefas, que foram executadas e flexibilizadas, buscando atender as necessidades da turma. Após a exposição das teorias, foi apresentada a proposta da tarefa embasada pela BOA (Base Orientadora da Ação) do tipo III, sendo esta adequada para aplicarmos o tipo de tarefa proposta.

No quarto momento, os licenciandos realizaram a ação e interpretaram a solução, ou seja, ministraram uma aula para os colegas da sala, mestranda estagiária, professor titular da turma e supervisor da disciplina. Em seguida, entregaram um relatório final das tarefas desenvolvidas na disciplina Didática da Matemática. Ocorreu também a avaliação e retroalimentação do processo de ensino e aprendizagem, que utilizou como estratégia

Recebido em: 10/02/2021

Aceite em: 09/08/2021 
de ensino a resolução de problemas. Foi o momento de realizar novos ajustes, tomar decisões e redefinir ações. Por último, foram analisados os dados coletados, a partir do relatório final da pesquisa, com evidências de aprendizagem por parte dos acadêmicos.

\section{DESCRIÇÃO E ANÁLISE DOS DADOS}

Durante as atividades de pesquisa, percebeu-se a possibilidade de analisar a mobilização dos conceitos teóricos da Atividade de Situações Problema Docente durante o processo da ensinagem. Para esta análise, tomou-se como momentos as próprias ações da Atividade de Situações Problema Docente, para o processo formativo dos acadêmicos que cursaram a disciplina Didática da Matemática. As análises da pesquisa ocorreram em quatro momentos, conforme descrito abaixo.

No primeiro momento (diagnóstico), observou-se habilidades e potencialidades prévias ao processo de ensino e aprendizagem, dificuldades na aprendizagem dos acadêmicos, sendo possível a identificação de novas aprendizagens que seriam trabalhadas ao longo da disciplina. Ficou evidenciada a assimilação dos licenciandos, quanto aos conceitos e epistemologia dos termos Didática e Aprendizagem Matemática, que seriam estudados no decorrer da disciplina. Buscou-se verificar se esses termos, no momento inicial das tarefas, eram novos para os licenciandos, ou se já tinham familiaridade com os mesmos, utilizando-se da teoria Histórico-Cultural, para relacionar conhecimentos científicos com a sua prática.

Os licenciandos demonstraram conhecimento a respeito da teoria HistóricoCultural de Vygotsky, inserida em ementas de disciplinas já cursadas, tais como: Didática Geral e Psicologia na Educação, que faz parte da grade curricular da Licenciatura em Matemática da UFRR. Observou-se nas falas dos licenciandos que a Atividade de Situações Problema Docente, como metodologia de ensino, fundamentada em Galperin, Talízina e Majmutov, Mendoza e Tintorer, evidenciou-se como novo conhecimento, sendo necessário o estabelecimento de um conjunto de ações docentes, com o intuito de solucionar o problema docente.

Finalizou-se o diagnóstico com o objetivo alcançado, pois foi possível verificar o real conhecimento dos acadêmicos em relação à temática, trabalhada ao longo da disciplina, possibilitando partir para o segundo momento, que correspondeu a construção

Recebido em: 10/02/2021

Aceite em: 09/08/2021 
do núcleo conceitual (planejamento), onde a professora delineou e orientou todo o processo para alcançar o potencial dos acadêmicos.

Assim, no segundo momento da pesquisa, foi realizado o planejamento do processo de ensino e aprendizagem dos licenciandos da zona de desenvolvimento real a potencial. Neste momento, foi construída a zona de desenvolvimento proximal, que favoreceu a formulação da base orientadora da ação geral, completa e independente. Selecionou-se o sistema de avaliação, levando em consideração a etapa mental em que os licenciandos se encontravam.

Utilizou-se a Atividade de Situações Problema Docente para resolução de problema como metodologia de ensino, onde se fez necessário analisar os conhecimentos prévios que os licenciandos deveriam dominar, para então, elaborar o planejamento da disciplina Didática da Matemática. Além de ser requisito obrigatório na Licenciatura em Matemática, tem como pré-requisito a disciplina Didática Geral, com o objetivo de desenvolver habilidades nos licenciandos através de métodos e técnicas para colocar em prática as estratégias metodológicas utilizando teorias de aprendizagem para melhorar o processo de ensino e aprendizagem da Matemática.

No terceiro momento da pesquisa, que compreendeu a Solução do Problema Docente (execução), a estagiária mestranda auxiliou os licenciandos na resolução das tarefas solicitadas ao longo da disciplina. Após a abordagem das teorias, procedeu-se com a apresentação da proposta das tarefas que foram embasadas pela BOA (Base Orientadora da Ação) do tipo III, sendo esta adequada para aplicarmos aos tipos de tarefas propostas, conforme já mencionado. Nesse momento, os acadêmicos elaboraram e resolveram diferentes tipos de tarefas avaliativas, tais como: sequência didática, plano de aula e relatório, fundamentados em Vygotsky, Leontiev, Galperin e Majmutov, como requisito para aprovação na disciplina.

Os licenciandos foram motivados a iniciar a construção da sequência didática e os planos de aulas, seguindo como princípios: o ensino problematizador de Majmutov, a resolução de problema como metodologia de ensino, teoria da atividade de estudo de Leóntiev e a formação das etapas mentais de Galperin. Deveriam seguir também uma 
estrutura básica com apresentação dos objetivos, conteúdos, metodologia, recursos didáticos, tarefas, avaliação e referências.

As sequências didáticas foram estruturadas seguindo as ações docentes: introdução, desenvolvimento e fechamento da aula, conforme as etapas metais de assimilação de Galperin. O conteúdo matemático foi de livre escolha. Os alunos optaram pelo Ensino Fundamental - Anos Finais e $1^{\text {a }}$ Série do Ensino Médio. O aluno A1 fez as tarefas solicitadas para o $6^{\circ}$ ano do Ensino Fundamental, abordando o objeto de conhecimento: Operações (adição, subtração, multiplicação e divisão) com números decimais. O Aluno A2 escolheu o objeto de conhecimento "Porcentagem e Frações", com tarefas direcionadas ao $6^{\circ}$ ano do Ensino Fundamental. O terceiro aluno A3, optou por desenvolver as tarefas para a $1^{\text {a }}$ Série do Ensino Médio, trabalhando o objeto de conhecimento "Progressões Aritméticas".

Conforme Neto (2015), a teoria de assimilação de Galperin considera que os estudantes sob a orientação do professor e sob um processo que segue etapas definidas, assimilam procedimentos gerais da tarefa intelectual como também de conhecimento.

Nesta fase, a mestranda estagiária e a professora responsável pela disciplina estiveram continuamente acompanhando a execução das tarefas dos licenciandos, retroalimentando e corrigindo o processo de ensino e aprendizagem sempre que foi preciso.

Na sequência didática e na elaboração do plano de aula, a construção do conhecimento foi realizada a partir da contextualização do tema sugerido pelos próprios licenciandos, de acordo com a afinidade de cada um, apresentando estrutura lógica e própria para as modalidades (Ensino Fundamental - Anos Finais e $1^{\text {a }}$ Série do Ensino Médio). Para explicar o conteúdo (parte teórica, relacionando com as teorias abordadas), apresentaram sinônimos para os termos técnicos, exemplificaram, fizeram analogias, respeitando a linguagem formal, de acordo com o nível de ensino.

Percebeu-se que os licenciandos se preocuparam em iniciar a sequência e o plano de aula com um diagnóstico, permitindo assim compreender o nível de partida da Atividade de Situações Problema Docente em relação aos objetos de conhecimento. A análise tinha o objetivo de verificar o ponto de partida dos alunos, permitindo assim o

Recebido em: 10/02/2021

Aceite em: 09/08/2021 
planejamento adequado do professor. Os licenciandos escolheram as estratégias de ensino, definindo-as na direção do processo de ensino e aprendizagem.

Tal percepção foi possível, a partir de narrativas dos participantes. O Aluno A2, por exemplo, expressou que utilizou como princípio na sua sequência didática, a inserção de "uma atividade que servisse de diagnóstico para saber o conhecimento prévio dos alunos, um elemento muito importante no processo de ensino aprendizagem, buscando saber nível de partida dos estudantes em relação à atividade que deseja formar, como Propõe Talízina. Aquilo que é chamado de Zona de desenvolvimento Real por Vigotsky (O que é sabido) ".

Tanto na sequência didática, quanto na elaboração do plano de aula ficou visível que os licenciandos se preocuparam em contextualizar os conteúdos, identificando estratégias para apresentá-los, representá-los, exemplificá-los, conectá-los e torná-los significativos, com base na realidade do lugar e do tempo nos quais as aprendizagens estão situadas. Segundo Barcelos et. al. (2020, p. 44) "O licenciando deve estar atento sobre as suas responsabilidades, uma vez, que educar é compartilhar saberes com crianças, jovens e adultos em uma sociedade complexa e em transformação diariamente".

Os licenciandos planejaram as aulas introduzindo o objeto de conhecimento com nível progressível, ou seja, elaboraram tarefas a partir do simples para o complexo, chamada por Talízina de etapa motivacional, pois segundo ela, caso não seja trabalhada durante todo o processo de ensino programado, esta pode comprometer as demais etapas no planejamento da formação da ação mental e dos conceitos (TALÍZINA, 1988).

Para o Aluno A3, “ a questão da motivação, mencionada pelos teóricos Talízina e Galperin, realmente é algo muito importante, pois o objetivo da aprendizagem e a motivação precisam se aproximar para o sucesso da atividade de estudo. Os alunos precisam estar motivados, para aprender".

No quarto momento - Interpretação da Solução (retroalimentação e correção) - os licenciandos apresentaram um relatório incluindo a sequência didática, plano e simulação de uma aula. Entre as contribuições que a teoria trouxe aos licenciandos em relação à disciplina Didática da Matemática, verificou-se na interação dos licenciandos com as tarefas realizadas, o desenvolvimento de uma prática reflexiva na ação docente.

Recebido em: 10/02/2021

Aceite em: 09/08/2021 
A aula simulada pelos acadêmicos, foi desenvolvida a partir de tarefas dialogadas, seminários, debates e discussões sobre o assunto, contextualizando a realidade do estudante e a sua prática de sala de aula, pois dois dos licenciandos tinham experiência (A1 e A2 com o PIBID e o outro, A3, com aulas ministradas em cursos preparatórios). A experiência permitiu aos licenciandos um melhor entendimento quanto à elaboração da sequência didática, plano de aula, simulação de aula, facilitando essa ponte entre teoria e prática. É importante ressaltar que as tarefas solicitadas na disciplina Didática da Matemática não foram aplicadas em turmas de Ensino Fundamental ou Médio. O intuito foi verificar se os acadêmicos tinham compreendido como diagnosticar, planejar, executar um planejamento, retroalimentar e corrigir o processo de ensino e aprendizagem, fazendo uso das ações da Atividade de Situações Problema Docente - ASPD.

O aluno A1 relatou que: “Os estudos de Vigotsky, em sua teoria histórica cultural e o processo de assimilação do homem estão dados pela experiência social, me ajudou a colocar em prática no plano de aula, adequando à realidade do aluno, seu dia a dia, para que chegue ao seu objetivo de aprendizagem”.

Sobre as atividades desenvolvidas, o aluno A2 relatou que percebeu " [...] o quão difícil é planejar e executar uma aula, e quão importante é ter em mãos teorias como as de Vigotsky, Talizina, Galperin, entre outros”. Além disso, expressou em seu relatório final o seguinte registro: "[...] foram inúmeras contribuições da disciplina para nossa formação acadêmica, uma vez que as teorias na área da educação em matemática que foram estudadas nos ajudarão bastante quando estivermos em sala de aula”.

$\mathrm{O}$ aluno A1 relatou ainda o fato de terem aprendido "[...] que muitos fatores externos podem interferir no aprendizado de um aluno, conforme mostram os estudos de Vigotsky, em sua teoria histórica cultural, pois o processo de assimilação do homem é dado também pela experiência social”.

Ficou evidenciado nas narrativas dos licenciandos que as tarefas realizadas contribuíram para sua formação enquanto futuros docentes, ao promover: o contato entre as teorias que se discutem no ambiente acadêmico e a realidade do campo profissional; a identificação com a docência; aprendizagens referentes à organização da aula; o planejamento do processo de ensino e aprendizagem; o desenvolvimento de saberes sobre

Recebido em: 10/02/2021

Aceite em: 09/08/2021 
a docência; conhecimento sobre os conteúdos curriculares do Ensino Fundamental e Médio, como também as trocas de experiências, através do diálogo entre os pares.

Percebeu-se que os licenciandos conseguiram as habilidades necessárias, alinhando as teorias abordadas aos trabalhos solicitados, pois ficou evidente na sequência didática, plano de aula e nas suas falas no momento das apresentações, seminários e na simulação da aula ministrada, o embasamento teórico apresentado.

Para Galperin, os novos tipos de atividade psíquica, a princípio, são assimilados, em forma externa, material, transformando-se em forma interna, psíquica. Esta transformação é orientada pelo sistema das características (parâmetros) independentes, constituindo o processo de transformação da atividade (CHIRONE, 2016).

No decorrer das aulas simuladas, os licenciandos ao ministrarem, demonstraram manter a lógica durante as explicações, introduzindo ideais e conceitos mais simples para dar sequência aos mais complexos, motivando assim os aprendizes. Preocuparam-se com os detalhes ao planejar os recursos didáticos que poderiam deixar as aulas mais atraentes. Buscaram desenvolver habilidades para uma aprendizagem desenvolvimental da atividade de situações problema, fazendo uso de problemas do cotidiano, considerando as necessidades do aprendiz, para que, dessa forma, fosse possível motivar os estudantes nas tarefas de ensino.

$\mathrm{Na}$ fala dos licenciandos ficou bem claro a importância dos recursos e materiais necessários para o desenvolvimento de suas aulas, fazendo uso de textos impressos, datashow, internet, áudios, vídeos, fotografias ou outras imagens, jogos, etc. Percebeu-se também o entendimento deles quanto a necessidade de avaliar o cumprimento dos objetivos de ensino, realizando correções pertinentes. Ficou claro nas falas dos licenciandos que o professor precisa estar atento, avaliando o processo ao longo da disciplina.

Nessa perspectiva, a disciplina Didática da Matemática permitiu aos licenciandos conhecer, analisar e refletir sobre seu futuro ambiente de trabalho. É importante compreender que as tarefas da disciplina se configuraram também como pesquisa e, como tal, exigiram coleta de dados, análise, discussões e relatório de tarefa detalhado, a partir do que foi observado, experimentado, analisado e concluído. Diante disso, percebeu-se

Recebido em: 10/02/2021

Aceite em: 09/08/2021 
que é na construção da identidade que os licenciandos da referida disciplina devem apostar em aperfeiçoamento, buscando assim: autonomia, responsabilidade e capacitação, que são características superimportantes para a valorização e atuação dos profissionais que atuam nesta área na atual sociedade complexa em que vivemos, buscando, dessa forma, melhorias não só para sua comunidade escolar como também para o município, estado e para o nosso país.

\section{CONSIDERAÇÕES FINAIS}

Durante as tarefas planejadas e desenvolvidas na disciplina Didática da Matemática, constatamos que os objetivos propostos foram alcançados, considerando que a metodologia utilizada, a partir das estratégias da Atividade de Situações Problema Docente, apresentaram resultados positivos.

A etapa zero foi muito importante para os licenciandos compreenderem a importância de motivar os alunos a explorarem os objetos de conhecimento. Observaram também que a segunda etapa, conhecida como diagnóstico inicial, apresentou dados que possibilitaram um planejamento com olhar mediador, presente na zona de desenvolvimento proximal de Vygotsky. No decorrer das outras etapas, foi perceptível nas falas dos licenciandos que a Atividade de Situações Problema Docente, fundamentada na teoria Histórico-Cultural, contribuiu para o planejamento, execução e internalização das ações de ensino e aprendizagem.

A pesquisa sugere a continuidade de estudos mais aprofundados com olhar na Atividade de Situações Problema Docente em Matemática. Enfatiza-se a possibilidade de aplicação das teorias a outros componentes curriculares, nas mais diversas áreas do saber, não se detendo apenas a Matemática.

Propõem-se as Ações da ASPD como metodologia para analisar as contribuições da Atividade de Situações Problema Docente, fundamentada em Leontiev, Galperin e Majmutov, para o processo formativo dos licenciandos na disciplina de Didática de Matemática do curso de Licenciatura em Matemática da Universidade Federal de Roraima.

Recebido em: 10/02/2021

Aceite em: 09/08/2021 


\section{REFERÊNCIAS}

ALVES, C.; HECKLER, V. TDIC na Formação de Professores em Ciências e Matemática. Revista Insignare Scientia - RIS, v. 1, n. 2, 10 abr. 2018.

BARCELOS DOS SANTOS, E.; MARTINS, M.; SILVEIRA RAMOS, M.; NETO, H.; MAZOCCO PANIZ, C. A importância do Programa de Residência Pedagógica na formação de professores no Instituto Federal Farroupilha, Campus São Vicente do Sul. Revista Insignare Scientia - RIS, v. 3, n. 1, p. 42-56, 4 jun. 2020.

BELO, Edileusa S V. Cartografias experienciais de formadores de professores de matemática: consciência de si e autoformação. 179f. Tese (Doutorado). Instituto de Educação Matemática e Cientifica, Universidade Federal do Pará, 2018.

BELO, Edileusa S V. Formadores de Professores de matemática. 150f. Dissertação (Mestrado). Instituto de Educação Matemática e Cientifica, Universidade Federal do Pará, 2012.

CHIRONE, Adriana Regina da Rocha. Aprendizagem de Equações do $1^{\circ}$ Grau a partir da Atividade de Situações Problema como Metodologia de Ensino, Fundamentada na Teoria de Formação por Etapas das Ações Mentais e dos Conceitos de Galperin. Boa Vista-RR, 2016. Dissertação (Mestrado em Ensino de Ciências) - Universidade Estadual de Roraima.

FIORENTINI, D.; LORENZATO, S. Investigação em educação matemática: percursos teóricos e metodológicos. 2ed. Campinas: Autores Associados, 2010. 240 p.

GONÇALVES; Tadeu Oliver. A constituição dos formadores de professores de matemática: a prática formadora. Belém: CEJUP, 2006.

MAJMUTOV, M. J. La Enseñanza Problémica. Habana: Pueblo y Revolución, 1983.

MENDOZA, H. J. G..; TINTORER, O. A Didática da Matemática fundamentada na teoria de formação por etapas das ações mentais de Galperin. In: Isauro Beltrán Núñez; Betânia Leite Ramalho. (Org.). P. Ya. Galperin e a teoria da assimilação mental por etapas: Pesquisa e experiências para um ensino inovador. 1ed.Campina - SP: Mercado de Letras, 2018a, v. 1, p. 125-153.

MENDOZA, H. J. G.; TINTORER, O. A contribuição do ensino problematizador de Majmutov na formação por etapas das ações mentais de Galperin. Revista Obutchénie, v. 2, p. 166-192, 2018 b.

MENDOZA, H. J. G.; TINTORER, Oscar. A Atividade de Situações Problema em Matemática. In: LONGAREZI, Andréa Maturano; PUENTES, Roberto Valdés. (Org.). Ensino, aprendizagem e desenvolvimento: fundamentos psicológicos e didáticos para o ensino desenvolvimental. 1ed.Uberlândia, MG: EDUFU, 2017, v. 1, p. 373-403.

Recebido em: 10/02/2021

Aceite em: 09/08/2021 
MOYSÉS, Lucia. Aplicações de Vygotsky à educação matemática. Campinas, SP: Papirus, 1997.

MOROSINI, Marília C. Professor do ensino superior: identidade, docência e formação. 2. ed. e Ampl. Brasília: Plano editora, 2001. 163 p.

NETO, Ronaldo Nunes. A atividade de situações problema na aprendizagem do conteúdo de fração fundamentada na teoria de formação por etapas das ações mentais de Galperin com os estudantes do $5^{\circ}$ ano da escola municipal Laucides Inácio de Oliveira. Boa Vista, 2015. Dissertação (Mestrado em Ensino de Ciências) Universidade Estadual de Roraima.

NÚÑEZ, Isauro B. O diagnóstico dos níveis da orientação da ação classificar: contribuição da teoria de P. Ya. Galperin. In.: FEITOSA, Raphael Alves; SILVA, Solonildo Almeida da (Orgs.). Metodologias emergentes na pesquisa em ensino de ciências. Porto Alegre: Editora Fi, 2018. Disponível em: http://www.editorafi.org. Acesso: novembro de 2018.

NÚÑEZ, I.B. e RAMALHO, B. L. A teoria da Formação Planejada das Ações Mentais e dos Conceitos de P. Ya. Galperin: contribuições para a Didática Desenvolvimental. Obutchénie: Revista de Didática e Psicologia Pedagógica, v.1, n.1, Uberlândia, MG, p.70-98, janeiro/junho, 2017.

PIMENTA, Selma G.; LIMA, Maria S. L. Estágio e docência. São Paulo: Cortez, 2012.

PIMENTA, Selma Garrido; ANASTASIOU, Léa das Graças. Docência no Ensino Superior- São Paulo: Cortez, 2010.

TALÍZINA, N. Psicología de la Enseñanza. Moscú: Progreso, 1988.

VYGOTSKY, L.S. Pensamento e linguagem. São Paulo: Martins Fontes, 2005.

VYGOTSKY, L. S. O desenvolvimento psicológico na infância. 1a Ed. São Paulo: Martins Fontes, 1988.

Recebido em: 10/02/2021

Aceite em: 09/08/2021 